\title{
BMJ Open Parental experience of child death in the paediatric intensive care unit: a scoping review
}

\author{
Sonoe Tezuka (D) , Kyoko Kobayashi
}

To cite: Tezuka S, Kobayashi K. Parental experience of child death in the paediatric intensive care unit: a scoping review. BMJ Open 2021;11:e057489. doi:10.1136/ bmjopen-2021-057489

- Prepublication history and additional supplemental material for this paper are available online. To view these files, please visit the journal online (http://dx.doi.org/10.1136/ bmjopen-2021-057489)

Received 21 September 2021 Accepted 06 December 2021

Check for updates

(c) Author(s) (or their employer(s)) 2021. Re-use permitted under CC BY-NC. No commercial re-use. See rights and permissions. Published by BMJ.

Child Health Nursing, Graduate School of Nursing, St Luke's International University, Tokyo Japan

Correspondence to Ms Sonoe Tezuka; 19dn010@sicn.ac.jp

\section{ABSTRACT}

Objective The purpose of this scoping review was to identify the experiences of parents who endured the death of their child in the paediatric intensive care unit (PICU) and what end-of-life care they perceived as supportive. Design Scoping review using the Preferred Reporting Items for Systematic Reviews and Meta-Analyses extension for Scoping Reviews guidance.

Data sources Four databases, PubMed, Embase, CINAHL and PsycINF0, were searched for studies published until 24 August 2021, with no limitation on the year of publication.

Eligibility criteria We identified qualitative studies published in English that focused on parents' experiences during the death of their child in the PICU and excluded studies conducted in non-PICU settings, such as neonatal intensive care units and emergency departments.

Data extraction and synthesis A five-step methodological approach ('identifying the research question', 'searching for relevant studies', 'selecting studies', 'charting the data' and 'collating, summarising and reporting the results') developed by Arksey and 0 'Malley was used to chart the purpose and methods of the study and the characteristics of the study participants. The extracted parental experiences were inductively summarised.

Results 0 f 435 articles, 14 studies conducted in seven countries were included in the final review. The background regarding the child's condition varied, including whether it was acute or chronic, and the length of stay in the PICU. Parents needed effective interaction with healthcare providers to fulfil their parental role and be involved in critical decision-making regarding their child's treatment in a rapidly evolving situation. The themes inductively extracted were 'parental suffering', 'roles and responsibilities of parents', 'information sharing', and 'support of parents by healthcare providers'.

Conclusions Although parent-healthcare provider interactions influence parents' experiences with their dying children in the PICU, by affecting parental roles and level of involvement, there is a lack of research focusing on improving these interactions.

\section{INTRODUCTION}

The majority of paediatric intensive care unit (PICU) deaths occur after the withdrawal or withholding of life-sustaining treatment. ${ }^{1-3}$ Approximately, $80 \%$ of infants with complex

\section{Strengths and limitations of this study}

We refined our search strategy and extracted inductive studies from four databases.

- The comprehensive search and inclusion of qualitative studies with evidence of parental voice provide practice recommendations.

- Children and families eligible for end-of-life care in the paediatric intensive care unit are inherently diverse and complex, and a focus on all settings will enhance holistic understanding.

- Effective collaboration between parents and healthcare providers requires a trusting relationship, which requires an understanding of the parent's experience.

- Since this scoping review focused on Englishlanguage literature and excluded grey literature, content in other languages and from non-peerreviewed sources may have been overlooked.

chronic diseases die in hospitals. ${ }^{4}$ In addition, approximately $60 \%-90 \%$ of in-hospital deaths in children occur in intensive care units. ${ }^{56}$ While the PICU is a place of advanced lifesustaining care delivery and recovery, it is also the place where most children die in hospitals. This means that parents must face overwhelmingly difficult life-limiting decisions for their loved ones.

The trajectories that children and families follow in the PICU are also variable. $^{78}$ According to one study, from the initial discussion about discontinuing lifesustaining treatment, the time it took for parents and healthcare providers to make a decision varied widely, from immediately to 19 days. $^{9}$ Physicians and nurses report that physicians usually initiate discussions about limiting life-sustaining treatments and that family members are rarely the first to bring up such discussions. ${ }^{10}$ Healthcare providers face communication barriers with parents, including making end-of-life (EOL) care decisions, discussions about not resuscitating and the transition to bereavement care. ${ }^{1112}$ Effective communication with parents can be 
difficult for healthcare providers, especially when there is a discrepancy between the information parents desire to be given and the real information. ${ }^{13}$

In contrast, some parents felt they could only consider withdrawing life-sustaining treatments after some indeterminate amount of time had passed. Several parents said that the combination of suffering without a chance for improvement would influence them to consider withdrawing life-sustaining treatments. ${ }^{14}$

Indeed, several discrepancies have been identified between the perspectives of parents and those of healthcare providers. ${ }^{15}$ In the PICU setting, parents are influenced by the behaviours and attitudes of healthcare providers. Although parental involvement is essential, sharing information and participating in the decisionmaking process may be limited.

Healthcare providers currently lead the participation of parents in decision-making, and medical professionals should consider and support individual situations to promote shared decision-making. In improving EOL care, it is vital to understand the experiences of parents whose children are facing imminent death. There is little evidence of effective interventions on the problems faced by parents who lose a child in the PICU. In order to improve and develop EOL care in the PICU, we decided that it would be appropriate to identify the current status and problems in this area through a scoping review focusing on evidence mapping. Therefore, the purpose of this scoping review was to identify the experiences of parents who experienced the death of their children in the PICU and what EOL care they perceived as supportive.

\section{METHODS}

We adhered to the Preferred Reporting Items for Systematic Reviews and Meta-Analyses extension for Scoping

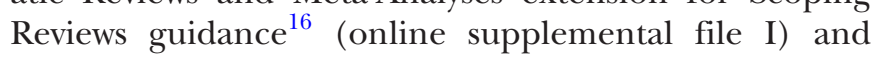
the five-stage methodological framework developed by Arksey and $\mathrm{O}^{\prime}$ Malley ${ }^{17}$ : identifying the research question, searching for relevant studies, selecting studies, charting the data and collating, summarising and reporting the results. Research questions are broad in nature, as intended to cover a wide area, so comprehensiveness and breadth are important in the search. The focus of this scoping review was to identify the experiences of parents who lost their children in the PICU and their recommendations for care. Therefore, the target population was defined as parents who had lost a child in the PICU, and the recommendations to healthcare providers derived from parents' experiences were defined as outcomes.

Electronic databases and search terms were explored through preliminary searches by the researcher (ST) to identify relevant studies. We checked whether the search results included references employed in existing literature reviews found in the database search and examined our search strategy until we reached a saturation point where no new references were found. The final search strategy was refined and determined through discussions between researcher (ST) and librarians. The inclusion and exclusion criteria for the selection of studies were discussed and agreed on by the researchers (ST and KK) to be based on the specific content of the research questions.

The databases searched included PubMed, Embase, CINAHL and PsycINFO. Articles published from the earliest database records to 24 August 2021 were included with no limitation on the year of publication. The search strategy for a single database is shown in table 1 , and the search strategy for all databases is shown in online supplemental supplemetnal II, table 2. The final databases searched results were exported into RefWorks, and duplicates were removed.

\section{Selection of sources of evidence}

Child death is overwhelming for parents with the added stress from the PICU environment. The main focus of this review was to map the existing evidence on parental experience and recommended care in the PICU setting. The inclusion criteria were qualitative research, parental experiences and perspectives related to EOL care in the PICU setting as the research objective, and qualitative research reported in English. Therefore, we excluded studies

\section{Table 1 Search strategy in PubMed database}

\begin{tabular}{|c|c|}
\hline Search & Query \\
\hline 1 & $\begin{array}{l}\text { "pediatric intensive care unit*"(Title/Abstract)OR "paediatric intensive care unit*"(Title/Abstract)OR "PICU"(Title/ } \\
\text { Abstract)OR "intensive care units, pediatric"(MeSH Terms) }\end{array}$ \\
\hline 3 & $\begin{array}{l}\text { "end of life care"(Title/Abstract)OR "Palliative Care"(Title/Abstract)OR "Terminal Care"(Title/Abstract)OR "grief } \\
\text { care"(Title/Abstract)OR "bereavement care"(Title/Abstract)OR "Terminal Care"(MeSH Terms] OR "Palliative } \\
\text { Care"(MeSH Terms) }\end{array}$ \\
\hline 4 & $\begin{array}{l}\text { "experience*“(Title/Abstract)OR "behavior*“(Title/Abstract)OR "perception”(Title/Abstract)OR } \\
\text { "perspective”(Title/Abstract)OR "Qualitative Research”(MeSH Terms] OR "Interviews as Topic"(MeSH Terms] } \\
\text { OR “Narration”(MeSH Terms] OR "Qualitative"(Title/Abstract)OR “interview*“(Title/Abstract)OR "narrati*"(Title/ } \\
\text { Abstract) }\end{array}$ \\
\hline 5 & \#1 AND \#2 AND \#3 AND \#4 \\
\hline
\end{tabular}


conducted in different settings, such as neonatal intensive care units, which primarily focus on very premature infants, and emergency departments, which have core concepts in diagnosing and treating illnesses, as these potentially impact the parental experience. Although bereavement from a child poses health problems for parents, follow-up studies of bereaved families who have lost a child were excluded from clarifying the experiences faced in the PICU. Studies of siblings and grandparents were excluded because the focus of this review was on parental experience. Noteworthily, in this scoping review, the term 'parent(s)' is used to refer to the child's primary caregiver(s), which could include biological or adoptive parents, grandparents, or other guardians.

\section{Critical appraisal of individual sources of evidence}

The eligibility of the selected primary qualitative studies was based on the inclusion of reliable statements of ethical considerations and verbatim parental voices cited to ensure the validity of the results. Because the method of data collection in qualitative studies can influence the results, we excluded studies that analysed descriptive responses inductively and limited the study to data collected through face-to-face or telephone interactions. Two researchers (ST and KK) were independently referenced to determine whether the studies met the eligibility criteria. Any differences of opinion were resolved through discussions among the researchers (ST and KK). From the selected study, we extracted results based on parents' experiences of staying in the PICU and the moment of bereavement with their children.

\section{Summarising and reporting}

The information recorded from the literature reviewed were author, year of publication, place of study, the purpose of study, study design, data collection methods and the parental experiences. The parental experiences of the qualitative data were inductively and descriptively summarised and themed from the data themselves, depending on the purpose and scope of the review, rather than being grouped into predetermined categories. The summaries and themes were completed independently by one researcher (ST) and confirmed by another researcher (KK). Disagreements between the two researchers (ST and KK) in constructing an inductive theme to summarise the results were resolved through discussion and expert opinion.

\section{Patient and public involvement}

Patients and the public were not involved in this scoping review.

\section{RESULTS}

A total of 435 articles were identified, of which 14 were included in the final review (figure 1). Duplicate references (141) were removed from the extracted articles. The titles and abstracts of 294 references were screened,

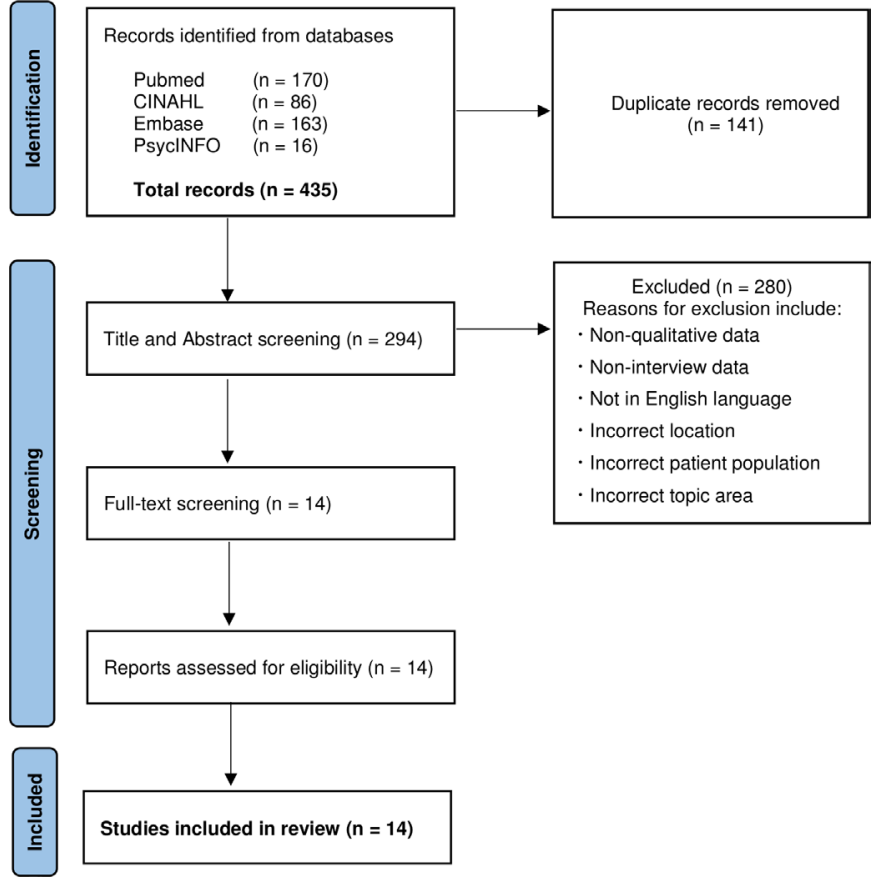

Figure 1 Flow diagram of study selection;.adapted from Page et al. ${ }^{42}$

and a total of 280 references were excluded. The studies were selected based on the inclusion and exclusion criteria. Reasons for exclusion included non-qualitative data, data not interviewed, not written in English, nonPICU settings, incorrect patient populations and study with incorrect topic areas such as treatment strategies.

\section{Study characteristics}

This scoping review identified studies published in the USA $(n=4)$, Australia $(n=3)$, the Netherlands $(n=3)$, the UK $(n=1)$, Italy $(n=1)$, Brazil, $(n=1)$ and Taiwan $(n=1)$ between 2009 and 2020. All references were qualitative studies that retrospectively examined parental experiences of EOL in the PICU and were analysed inductively. From each study, we extracted the timing of the parental interview, the child's age at the time of death, the length of the child's stay in the PICU and the child's medical condition. Detailed characteristics of the included studies are presented in online supplemental III, table 3 .

\section{Parental experience}

Parents needed effective interaction between themselves and healthcare providers in the process of fulfilling their parental role and being involved in critical decisionmaking regarding their children's treatment in a rapidly evolving situation. The themes inductively extracted from the 14 studies were 'parental suffering', 'roles and responsibilities of parents', 'information sharing' and 'support of parents by healthcare providers'.

\section{Parental suffering}

Parents were vulnerable due to anxiety, fear, conflict and information overload. ${ }^{19}$ They reported experiencing an unrealistic feeling of being cut-off from the outside 
world, triggered by witnessing their children's resuscitation and the moment of collapse. ${ }^{20}$ They lost control and felt alone. ${ }^{20}$

They had ambivalent emotions; a need to relieve their children's suffering and a fear of losing their children. ${ }^{18}$ After being told that their children would not survive, it became essential for parents to not give up hope. ${ }^{21}$ Even in the face of overwhelming evidence that their children's death was imminent, parents wanted to hold onto the hope that their children would survive. ${ }^{18} 192223$ Parents reported ambivalence about their involvement in the EOL decision-making process. There was the importance of being informed and involved in care; on the other hand, some parents did not want to decide to discontinue life-sustaining treatment. ${ }^{18} 1923$ In addition, when parents are involved in decision-making, their decisions need to be approved and supported by healthcare providers. ${ }^{18} 19$ Involvement in the decision-making process regarding stopping life-sustaining treatments or making Do Not Resuscitate orders became overwhelmingly challenging for parents. ${ }^{1823}$ However, they were comforted by making decisions that they thought were best for their children. ${ }^{18}$ Some parents spoke of turning to outside forces and adjusting their attitudes, leaving it to divine providence or fate to determine whether their children would survive. ${ }^{23}$

\section{Roles and responsibilities of parents}

Parents described their parental responsibility for their children's quality of care and implementing their parental duties as parental roles. ${ }^{19} 212425$ Butler $^{21}$ noted changes in the relationship between parents and medical personnel during the PICU stay, with significant changes in the lifesaving phase and the perception of the child's death. During the life-saving phase, most parents reported that their role was to step back and let the medical personnel protect their child and ensure that life-saving procedures were carried out without delay. As parents became more aware of their children's death, the relationship between them and the healthcare providers became more cooperative and shifted towards participation in the child's care. ${ }^{21}$ Parents also monitored the care being delivered by healthcare providers to ensure that their children received the best possible care, questioning and seeking information to minimise their distress and prevent unnecessary tests and treatments from being administered. ${ }^{21} 25$ When healthcare providers thwarted attempts to reconstruct parental roles, parents became observers rather than participants, and a sense of teamwork was lost. ${ }^{21} 26$

Moreover, Lamiani ${ }^{19}$ stated that parents experience the loss of opportunities to care for their children during crises, leaving treatment to the medical establishment. Parents emphasised the need to be recognised for their parental roles and be involved in their children's care as partners.

For the parent's role as part of a team with the medical professionals, they needed to understand what was happening. ${ }^{25}$ Gordon ${ }^{25}$ reported on the experience of a parent who was unable to fulfil her responsibility to participate in the team due to a lack of communication. For parents to be advocates for their children, they need to share information, but this high level of responsibility brings tension and stress. ${ }^{24}$

\section{Information sharing}

Understanding accurate information and participating in the decision-making process is important for parents and requires professional communication by healthcare providers. ${ }^{18} 20$ 25-29 Honest, transparent and frequent information sharing from healthcare providers is essential, ${ }^{182025262829}$ but parents need to understand that their children's condition is complex and subjected to uncertainty. ${ }^{25}$ Michelson ${ }^{29}{ }^{30}$ reported on a parent's experience of sharing information through informal communication within the time constraints of a rapidly evolving situation. The parents requested that the information be given verbally and in writing as soon as possible. ${ }^{28}$ Information sharing that was helpful to parents included explaining without technical terms, simplifying information, explaining repeatedly and being informed of what to expect next. ${ }^{26}$ Falkenburg et $a l^{20}$ also reported that parents could understand and interpret the situation as they were briefed one by one about what the doctors were thinking and what they were going to do.

\section{Trusting relationships with healthcare providers}

Trusting relationships with healthcare providers was meaningful in supporting parents of terminally ill children. ${ }^{1820212628}$ Mitchell et al ${ }^{18}$ reported that the presence of a trusted healthcare professional played an important role when serious decisions were made. Parents were also sensitive to changes in the non-verbal communication of healthcare professionals. ${ }^{18}$ This meant that when the child's condition worsened, or at the moment of dying, parents received implicit messages through the actions of medical professionals. ${ }^{18}$ It was important for parents to be given an environment to say goodbye to their children in an appropriate setting. ${ }^{19427}$ The humanity of the healthcare providers shown through personal interaction and emotional sharing made the parents feel connected and comfortable. $^{202628}$

\section{Support of parents by healthcare providers}

Parents urged healthcare providers to enable their children to live as long as possible, relieve their suffering, ensure their comfort and adjust their care according to changes, so that the best possible care was provided to the child. ${ }^{21}$ Being there for the parents and supporting them, helping them get used to the PICU environment and going above and beyond to meet the family's needs helped them. ${ }^{26}$ This also included referrals to outside support agencies for parents and support for siblings. ${ }^{28}$

Because the PICU environment creates a physical distance between parents and children, support from healthcare providers for parents to touch and hold their children is essential. ${ }^{1821262731}$ Some parents discussed how involving them in their children's physical care 
and supporting that process helped them rebuild their parental roles. ${ }^{21}{ }^{26}$ Practical support for parental self-care was also needed, such as resources for parents to take breaks while accompanying their children. ${ }^{26}$

Parents reported about the need for a private space to spend time with their children, as there was no privacy in the PICU. ${ }^{19} 24{ }^{28}$ Furthermore, it is important for healthcare providers to be prepared to allow families to choose how they would like to be attended to at the moment of death, when the child is released from treatment and restraints, and to have family time according to their wishes. 192428

\section{DISCUSSION}

In a review of parental perceptions of quality EOL care by Longden, ${ }^{32}$ all included studies involved the parents of children with different disease processes, rather than a uniform sample, and information from parents was obtained at different times along the grief trajectory. The same was true for this scoping review, with a common background being the loss of a child due to a decision to withhold or withdraw treatment in the PICU. The findings from this study offer many directions for improvements in EOL care in the PICU, as suggested by the bereaved parents themselves. The results of this scoping review emphasise the importance of information sharing and practical care for distressed parents to involve the parents in parental roles and responsibilities in EOL care in the PICU. Nonetheless, developing specific intervention strategies poses several challenges. For example, healthcare providers were seen to mishandle parental hope. ${ }^{26}$ This occurred when they either dispelled parental hope too soon or continued to incite hope despite clear indications that the child was dying. Another example is that the parents wanted to have regularly scheduled conferences during their stay in the PICU, but fast-changing clinical events and physician time constraints prevented the opportunity for explanations that satisfied the parents. ${ }^{30}$ Although information sharing and decisionmaking often occur informally at the bedside, ${ }^{33}$ not many studies have focused on the role of the nurses responsible for much of the care at the bedside. ${ }^{34}$ Barriers to decisionmaking and communication are often exacerbated by time constraints, lack of trust and limited opportunities to build relationships with parents. The timing of healthcare providers concerning information sharing needs to be determined appropriately in each case, but the criteria for such decisions are unclear. Meert et $a l^{35}$ suggest that a parent's perceptions and desires after the death of a child may or may not be related to the parent's actual needs at the time of death. The development of healthcare providers' skills in critical aspects of care delivery that are important from these parents' perspectives may improve the delivery of EOL care to children and their families but needs to be further explored for implementation.

Bereaved parents who have lost a child in the PICU are known to experience adverse health outcomes later in life. ${ }^{36-38}$ The research participants in this scoping review were potentially vulnerable. The fact that the bereaved parents of the studies in this scoping review were participants who could respond to the research request and discuss their experiences is a bias that should be considered. Bereaved parents who chose not to participate may have had different experiences. Parental experience in the context of EOL was influenced by multifaceted and complex factors, including the child's condition and relationship with healthcare providers. Also, the support of healthcare providers was essential for the parents to stay with their dying children, fulfil their roles and responsibilities as parents and be confident that they had chosen the best care for their children. It has been noted that there are many barriers to the practice of EOL care. In general, paediatric EOL decision-making is known to pose ethical dilemmas for healthcare providers. ${ }^{39} 40$ Research is needed to recognise the gaps that arise from the different positions of both parents and healthcare providers, understand the role of healthcare providers as expected by parents and understand strategies to promote interaction.

This review included studies from several countries, and the sample had a variety of conditions in the background, including developmental stage, child's disease trajectory and whether the disease was acute or chronic. The decision to withhold or withdraw treatment is significantly influenced by a country's laws and an institution's organisational culture. Qualitative research also needs to be cognizant of the concern that potential bias due to racial, economic, religious and cultural differences, and the philosophical underpinnings of the study may influence the results. Mortality in the PICU of five US centres was reported to be $2.39 \%$, with a range of $1.85 \%-3.38 \%{ }^{3}$ However, in the Mozambican PICU, the mortality rate was $25 \%$, and overall mortality was high compared with that of high-income countries. ${ }^{41}$ Studies on PICUs in low-income and middle-income countries are scarce, and the experience of parents who have lost a child may be different due to lack of medical resources and staff training.

\section{Limitations}

There are some limitations to this scoping review. To increase the pace and feasibility of our review, we excluded non-English literature, possibly missing potential parental experiences from non-English-speaking countries. The recommendations identified in the review are based on qualitative research and are challenging to generalise, although we provide data on the characteristics of the research and recommendations for future research for generalisation and use.

\section{CONCLUSIONS}

This review provides practical implications through evidence from studies that have focused on the unique and vulnerable experiences of parents of children dying in the PICU. Parents' experience with dying children 
in the PICU was a decision-making process influenced by their relationship with healthcare providers, and the interaction between the child, parent and healthcare provider influenced the EOL care, parent role and level of involvement. Parents had conflicting emotions as they struggled with the conflicts surrounding EOL care decision-making while, at the same time, holding onto hope until the moment of their children's death. Therefore, healthcare providers must provide information and have compassionate attitudes that consider the ambivalence of parents, encourage their participation and collaboratively pursue the best possible care for their children.

Acknowledgements Thank you to Akiko Shindo, St. Luke's International University librarian, for her invaluable assistance in assuring the completeness of the literature search.

Contributors Study design: ST, critically reviewed the study proposal: KK, analysis and interpretation of data: ST and KK, drafting of the manuscript: ST, critical revision of the manuscript for content: ST and KK, guarantor: ST.

Funding The authors have not declared a specific grant for this research from any funding agency in the public, commercial or not-for-profit sectors.

Competing interests None declared.

Patient consent for publication Not applicable.

Ethics approval This study does not involve human participants.

Provenance and peer review Not commissioned; externally peer reviewed.

Data availability statement All data relevant to the study are included in the article or uploaded as supplemental information. Not applicable.

Supplemental material This content has been supplied by the author(s). It has not been vetted by BMJ Publishing Group Limited (BMJ) and may not have been peer-reviewed. Any opinions or recommendations discussed are solely those of the author(s) and are not endorsed by BMJ. BMJ disclaims all liability and responsibility arising from any reliance placed on the content. Where the content includes any translated material, BMJ does not warrant the accuracy and reliability of the translations (including but not limited to local regulations, clinical guidelines, terminology, drug names and drug dosages), and is not responsible for any error and/or omissions arising from translation and adaptation or otherwise.

Open access This is an open access article distributed in accordance with the Creative Commons Attribution Non Commercial (CC BY-NC 4.0) license, which permits others to distribute, remix, adapt, build upon this work non-commercially, and license their derivative works on different terms, provided the original work is properly cited, appropriate credit is given, any changes made indicated, and the use is non-commercial. See: http://creativecommons.org/licenses/by-nc/4.0/.

ORCID iD

Sonoe Tezuka http://orcid.org/0000-0002-7989-0573

\section{REFERENCES}

1 Fraser LK, Miller M, Draper ES, et al. Place of death and palliative care following discharge from paediatric intensive care units. Arch Dis Child 2011;96:1195-8.

2 Carter BS, Howenstein M, Gilmer MJ, et al. Circumstances surrounding the deaths of hospitalized children: opportunities for pediatric palliative care. Pediatrics 2004;114:e361-6.

3 Burns JP, Sellers DE, Meyer EC, et al. Epidemiology of death in the PICU at five U.S. teaching hospitals*. Crit Care Med 2014;42:2101-8.

4 Feudtner C, DiGiuseppe DL, Neff JM. Hospital care for children and young adults in the last year of life: a population-based study. BMC Med 2003;1:3.

5 Feudtner C, Kang TI, Hexem KR, et al. Pediatric palliative care patients: a prospective multicenter cohort study. Pediatrics 2011;127:1094-101.

6 Meert KL, Keele L, Morrison W, et al. End-of-life practices among tertiary care PICUs in the United States: a multicenter study. Pediatr Crit Care Med 2015;16:e231-8.
7 McCallum DE, Byrne P, Bruera E. How children die in hospital. J Pain Symptom Manage 2000;20:417-23.

8 ten Berge J, de Gast-Bakker D-AH, Plötz FB. Circumstances surrounding dying in the paediatric intensive care unit. BMC Pediatr 2006;6:22.

9 Oberender F, Tibballs J. Withdrawal of life-support in paediatric intensive care--a study of time intervals between discussion, decision and death. BMC Pediatr 2011;11:39.

10 Burns JP, Mitchell C, Griffith JL, et al. End-of-life care in the pediatric intensive care unit: attitudes and practices of pediatric critical care physicians and nurses. Crit Care Med 2001;29:658-64.

11 Contro NA, Larson J, Scofield S, et al. Hospital staff and family perspectives regarding quality of pediatric palliative care. Pediatrics 2004;114:1248-52.

12 Michelson KN, Emanuel L, Carter A, et al. Pediatric intensive care unit family conferences: one mode of communication for discussing end-of-life care decisions. Pediatr Crit Care Med 2011;12:e336-43.

13 Truog RD, Meyer EC, Burns JP. Toward interventions to improve end-of-life care in the pediatric intensive care unit. Crit Care Med 2006;34:S373-9.

14 Michelson KN, Koogler T, Sullivan C, et al. Parental views on withdrawing life-sustaining therapies in critically ill children. Arch Pediatr Adolesc Med 2009;163:986-92.

15 Beckstrand RL, Rawle NL, Callister L, et al. Pediatric nurses' perceptions of obstacles and supportive behaviors in end-of-life care. Am J Crit Care 2010;19:543-52.

16 Tricco AC, Lillie E, Zarin W, et al. PRISMA extension for scoping reviews (PRISMA-ScR): checklist and explanation. Ann Intern Med 2018;169:467-73.

17 Arksey H, O'Malley L. Scoping studies: towards a methodological framework. Int J Soc Res Methodol 2005;8:19-32.

18 Mitchell S, Spry JL, Hill E, et al. Parental experiences of end of life care decision-making for children with life-limiting conditions in the paediatric intensive care unit: a qualitative interview study. $B M J$ Open 2019;9:e028548.

19 Lamiani G, Giannini A, Fossati I, et al. Parental experience of end-of life care in the pediatric intensive care unit. Minerva Anestesiol 2013;79:1334-43.

20 Falkenburg JL, Tibboel D, Ganzevoort RR, et al. The importance of parental connectedness and relationships with healthcare professionals in end-of-life care in the PICU*. Pediatr Crit Care Med 2018;19:e157-63.

21 Butler AE, Hall H, Copnell B. Becoming a team: the nature of the parent-healthcare provider relationship when a child is dying in the pediatric intensive care unit. J Pediatr Nurs 2018;40:e26-32.

22 Falkenburg JL, van Dijk M, Tibboel D, et al. The fragile spirituality of parents whose children died in the pediatric intensive care unit. $J$ Health Care Chaplain 2020;26:117-30.

23 Liu S-M, Lin H-R, Lu FL, et al. Taiwanese parents' experience of making a "do not resuscitate" decision for their child in pediatric intensive care unit. Asian Nurs Res 2014;8:29-35.

24 McGraw SA, Truog RD, Solomon MZ, et al. "I was able to still be her mom"--parenting at end of life in the pediatric intensive care unit. Pediatr Crit Care Med 2012;13:e350-6.

25 Gordon C, Barton E, Meert KL, et al. Accounting for medical communication: parents' perceptions of communicative roles and responsibilities in the pediatric intensive care unit. Commun Med 2009;6:177-88.

26 Butler AE, Copnell B, Hall H. "Some were certainly better than others" - Bereaved parents' judgements of healthcare providers in the paediatric intensive care unit: A grounded theory study. Intensive Crit Care Nurs 2018;45:18-24.

27 El Halal GMCA, Piva JP, Lago PM, et al. Parents' perspectives on the deaths of their children in two Brazilian paediatric intensive care units. Int J Palliat Nurs 2013;19:495-502.

28 Butler AE, Copnell B, Hall H. When a child dies in the PICU: practice recommendations from a qualitative study of bereaved parents. Pediatr Crit Care Med 2019;20:e447-51.

29 Michelson KN, Patel R, Haber-Barker N. End-of-life care decisions in the PICU: roles professionals play. Pediatr Crit Care Med 2013;14:e34-44.

30 Michelson KN, Emanuel L, Carter A, et al. Pediatric intensive care unit family conferences: one mode of communication for discussing end-of-life care decisions*. Pediatr Crit Care Med 2011;12:e336-43.

31 Falkenburg JL, Tibboel D, Ganzevoort RR, et al. Parental physical proximity in end-of-life care in the PICU. Pediatr Crit Care Med 2016;17:e212-7.

32 Longden JV. Parental perceptions of end-of-life care on paediatric intensive care units: a literature review. Nurs Crit Care 2011;16:131-9. 
33 Lewis-Newby M, Sellers DE, Meyer EC, et al. Location of clinicianfamily communication at the end of life in the pediatric intensive care unit and clinician perception of communication quality. J Palliat Med 2020;23:1052-9.

34 Meyer EC, Burns JP, Griffith JL, et al. Parental perspectives on end-of-life care in the pediatric intensive care unit. Crit Care Med 2002;30:226-31.

35 Meert KL, Eggly S, Pollack M, et al. Parents' perspectives on physician-parent communication near the time of a child's death in the pediatric intensive care unit. Pediatr Crit Care Med 2008:9:2-7.

36 Meert KL, Shear K, Newth CJL, et al. Follow-up study of complicated grief among parents eighteen months after a child's death in the pediatric intensive care unit. J Palliat Med 2011;14:207-14.

37 Hawthorne DM, Youngblut JM, Brooten D. Parent Spirituality, Grief, and Mental Health at 1 and 3Months After Their Infant's/Child's Death in an Intensive Care Unit. J Pediatr Nurs 2016;31:73-80.
38 Brooten D, Youngblut JM, Caicedo C, et al. Parents' Acute Illnesses, Hospitalizations, and Medication Changes During the Difficult First Year After Infant or Child NICU/PICU Death. Am J Hosp Palliat Care 2018;35:75-82.

39 Jacobs HH. Ethics in pediatric end-of-life care: a nursing perspective. J Pediatr Nurs 2005;20:360-9.

40 Solomon MZ, Sellers DE, Heller KS, et al. New and lingering controversies in pediatric end-of-life care. Pediatrics 2005;116:872-83.

41 Punchak M, Hall K, Seni A, et al. Epidemiology of disease and mortality from a PICU in Mozambique. Pediatr Crit Care Med 2018;19:e603-10.

42 Page MJ, McKenzie JE, Bossuyt PM, et al. The PRISMA 2020 statement: an updated guideline for reporting systematic reviews. BMJ 2021;372:n71. 